\title{
Role of qualitative research in exercise science and sports medicine
}

\author{
Catherine E Draper (MA, PhD) \\ UCT/MRC Research Unit for Exercise Science and Sports Medicine, Sports Science Institute of South Africa, Cape Town
}

\begin{abstract}
Qualitative research is featuring more frequently in health sciences research, a field in which the 'hard sciences' and statistics have traditionally dominated. For example, within the fields of exercise science and sports medicine, qualitative research methods are included to evaluate intervention programmes. These methods are also being used in studies that require measurement of behavioural perspectives, such as an understanding of individuals' motivations, attitudes, beliefs and perceptions. Qualitative research methods are also becoming increasingly useful in the investigation of contextual factors that impact on physical activity and sporting performance. The purpose of this article is to clarify the role of qualitative research in exercise science and sports medicine and provide the reader with a basic understanding of the basis of qualitative research. Qualitative data collection and analysis, sampling strategies in qualitative research, the role of the qualitative researcher, and issues of scientific rigour regarding qualitative research will be addressed.
\end{abstract}

\section{Introduction}

Qualitative, in the context of research, refers to 'quality in the sense of hallmarks, features, character, nuances, complexity, or nature of the phenomenon under study'. Qualitative research methods are the strategies used in the process of collecting, organising and interpreting text obtained through observation, or from communication with individuals or groups.

Qualitative research is used most commonly in the social sciences, such as psychology, sociology and social anthropology, and qualitative research methods are also used frequently in market research. However, the qualitative approach and qualitative methods are now being used more frequently in health sciences research, a field in which the 'hard sciences' and statistics have traditionally

\section{CORRESPONDENCE:}

\section{Catherine E Draper}

UCT/MRC Research Unit for Exercise Science and Sports Medicine

Sports Science Institute of South Africa

Boundary Road

Newlands 7700

Cape Town, South Africa

Tel: 27-21-650-4567

Fax: 27-21-686-7530

E-mail: catherine.draper@uct.ac.za dominated. The purpose of this article is to clarify the role of qualitative research in exercise science and sports medicine and provide the reader with a basic understanding of qualitative research.

\section{Where qualitative research is used in exercise science and sports medicine}

Within the fields of exercise science and sports medicine, qualitative research methods are being included more frequently in studies designed to evaluate programmes. For example, programmes that need to be evaluated may have a health promotion focus, such as school- and community-based programmes promoting physical activity, or may be sport related, such as a life skills programme for elite athletes. In programme evaluation qualitative research methods are particularly helpful when evaluating less tangible outcomes that are difficult to quantify, e.g. an evaluation of the participants' experiences of the programme. If these methods are properly implemented they can provide valuable insight into factors contributing to success and/ or failure of programmes, including both individual and contextual factors, as well as the strengths and weakness of a programme.

Sometimes studies in exercise science and sports medicine require measurement of behavioural perspectives such as an understanding of individuals' motivations, attitudes, beliefs and perceptions. These factors are difficult to assess without using qualitative research methods. Qualitative methods are also becoming increasingly useful in the investigation of contextual factors that impact on physical activity and sporting performance.

\section{Collecting qualitative data}

The main methods of collecting qualitative data are in-depth interviews, focus groups, observation and open-ended questions in questionnaires. An open-ended question requires a response from the participant rather than merely choosing an option from a provided list of options.

In-depth interviews can be described as conversations between an interviewer and interviewee, where the interviewer's main role is to listen carefully to the interviewee and frame questions around the interviewee's responses. In this context the interviewee is not so much a subject under examination, but more a partner, having an active role in directing the interview discussion and bringing the interviewer to a point of understanding his or her unique perspective. In-depth interviews are generally structured around relatively general, open-ended guide questions. ${ }^{2}$ Interviews are most useful in studies where it is likely that there will be a range of individual perspectives and experiences.

Key informant interviews are a type of in-depth interviews. Key informants are defined as individuals who are knowledgeable in a particular area, or who hold special status or skills. These types of informants are able to share their knowledge and skills, as well as their unique perspectives, observations and insights to which the 
researcher would otherwise not have access; these help to enrich the understanding of the researcher. ${ }^{3}$

A focus group can be defined as a group of individuals, usually no more than 8 , who are guided by a group facilitator to engage in a relatively informal discussion that is centred around a specific issue or topic. ${ }^{4}$ The facilitator's role is to pose questions to the group, just as in an in-depth interview, to generate discussion and encourage group members to participate and interact with one another, ${ }^{4}$ as well as to listen carefully and learn from the members of the group. ${ }^{5}$ Focus groups are most useful in studies where it is likely that individuals will share common views or common experiences, such as being in a team together, or participating in the same programme.

\section{Purposive sampling and role of the researcher}

One of the foundational aspects of qualitative research is that it aims for information richness 6 and the understanding of social processes. ${ }^{7}$ This distinguishes it from quantitative research, which aims for generalisability. Therefore, qualitative research requires a different strategy for sampling research participants - purposive sampling. Purposive sampling is a type of sampling that selects specific individuals or groups because they match criteria that are necessary for the investigation of whatever is being studied. This approach to sampling allows the researcher to explore particular issues relevant to the research, as well as to include particular key informants who can offer important and distinctive knowledge to the researcher. ${ }^{3,7}$ It should however be noted that in qualitative research, even though samples are not randomised, they should represent a range of individuals that would present the diverse views within the population under investigation.

In contrast to quantitative researchers, qualitative researchers are seen as research instruments, ${ }^{3,7-9}$ as they become part of the research process. ${ }^{9}$ Therefore, it is highly unlikely that the researcher will be able to take on a completely neutral or objective stance in this process. ${ }^{8}$ The qualitative approach holds that the relationship between the researcher and research process should be considered and revealed throughout the process, and that in acknowledging this relationship, bias is not eliminated, but is accounted for. ${ }^{3,10}$ This influence of the researcher (his/her background, characteristics and position) on the research process is termed 'reflexivity', and is accepted as part of the methodology in qualitative research. Qualitative researchers are indeed encouraged to acknowledge its presence. $^{3,8,10}$

\section{Qualitative data analysis}

Perhaps the most daunting aspect of qualitative research is qualitative data analysis. In essence, the analysis of qualitative data has similarities to statistical analysis of quantitative data, as it also involves a process of coding and categorising data. Qualitative data analysis is essentially a process of data reduction in which the researcher selects, focuses, simplifies and categorises data, thereby dividing it into more manageable pieces so that the researcher can interpret the data. ${ }^{9}$ This process may be inductive, if patterns, themes and categories are derived from the data itself, or deductive, if categories are introduced either at the start of, or part of the way through the analysis, and data are analysed according to this framework. ${ }^{3}$

In terms of the actual process of qualitative data analysis, guidelines and conventions exist that can assist researchers in this process. $^{3}$ The method of analysis should be verifiable and carried out systematically, ${ }^{11}$ which often makes it time consuming. However, there are computer programmes that have been designed to reduce the time of coding and categorising, although these programmes still require the researcher to do the thinking and to guide the analysis.

\section{'Soft' science?}

The main criticism of qualitative research is that it lacks scientific rigour, specifically around issues of validity (i.e. are research findings credible?), reliability (i.e. do research instruments measure what they are supposed to measure?), reproducibility (i.e. can the research be repeated?), and generalisability (i.e. can the findings from a sample be extrapolated to the rest of the population from which the sample is taken?). However, good qualitative researchers will argue that this is not the case and that validity is upheld using multiple research methods called triangulation. ${ }^{7,8}$ Apart from methodological triangulation, data triangulation can be employed, which uses data from different sources, and possibly from different settings, at different points in time. ${ }^{8}$ Investigator triangulation involves a team of researchers, and theory triangulation can be adopted where researchers compare the data to a number of hypotheses. ${ }^{12}$

Triangulation can also refer to the use of qualitative and quantitative methods in the same study, and underlying this is the understanding that quantitative and qualitative research should not compete for superiority, but rather complement each other.

\section{Summary}

There are ways in which good qualitative researchers address issues of rigour, and ultimately produce information that can be reported and applied outside of the research setting. This rests on the understanding that qualitative research methods form part of a systematic and reflective process that develops knowledge that can be shared and challenged. ${ }^{10}$ It may be said that quantitative research answers the important questions of 'who?', 'what?', 'where?', and 'when?' , and qualitative research contributes by helping to answer the 'why?' questions. Within the field of exercise science and sports medicine, there is not only a plethora of 'why?' questions that need answering, but also a vast array of issues and phenomena that are difficult, if not impossible, to quantify. Thus, quantitative data can provide a framework or skeleton for understanding something, and qualitative data can fill in the gaps and provide the 'flesh'.

\section{REFERENCES}

1. Malterud K. The art and science of clinical knowledge: evidence beyond measures and numbers. Lancet 2001;358:397-400.

2. Rubin HJ, Rubin IS. Qualitative interviewing: the art of hearing data. Thousand Oaks, Calif.: Sage; 1995.

3. Patton MQ. Qualitative research and evaluation methods. 3rd ed. Thousand Oaks, Calif.: Sage; 2002.

4. Wilkinson S. Focus group research. In: Silverman D, ed. Qualitative research: theory, method and practice. London: Sage; 1997. p. 177-199.

5. Morgan DL. The focus group guidebook. The focus group kit, vol. 1. Thousand Oaks, Calif.: Sage; 1998.

6. Kuzel AJ. Sampling in qualitative inquiry. In: Crabtree BF, Miller WL, eds. Doing qualitative research. Thousand Oaks, Calif.: Sage, 1992; p.31-44.

7. Mays N, Pope C. Rigour and qualitative research. BMJ 1995;311:109112.

8. Flick U. An introduction to qualitative research. London: Sage; 1998.

9. Marshall C, Rossman GB. Designing qualitative research. 2nd ed. Thousand Oaks, Calif.: Sage; 1995.

10. Malterud K. Qualitative research: standards, challenges, and guidelines. Lancet 2001;358:483-488.

11. Krueger RA. Analyzing and reporting focus group results. The Focus Group Kit, Vol. 6. Thousand Oaks, Calif.: Sage; p. 1998.

12. Seale C. The quality of qualitative research. London: Sage; 1999. 